\title{
DETC2001/DAC-21125
}

\section{IMPROVING COMMONALITY IN CUSTOM PRODUCTS USING PRODUCT PLATFORMS}

\author{
Ronald S. Farrell ${ }^{1}$ and Timothy W. Simpson ${ }^{2 *}$ \\ Department of Mechanical \& Nuclear Engineering \\ The Pennsylvania State University \\ University Park, PA 16802
}

\begin{abstract}
Many companies find it difficult to maintain commonality and economies of scale in products with strict customer design requirements that may vary greatly from contract-to-contract or piece-to-piece. These strict and varied requirements typically result in highly customized products that are costly to manufacture, involve small production runs, and require long delivery times. In this paper we discuss how the strategic incorporation of product platforms into the design process can leverage the design effort of individually customized products. The example involves the design of cross-sections for yokes used to mount valve actuators in the nuclear power industry. Through this example we demonstrate the process of creating a market segmentation grid, choosing a targeted segment, creating a product platform for the yoke cross-section, and subsequently defining the yoke product family. Reducing the number of yoke patterns when manufacturing yoke castings will generate the most significant savings since the proposed modular architecture for pattern construction reduces the number of new yoke patterns. Implementation of the yoke platforms will also reduce design cycle time and costs, shorten quotation and lead times, and improve overall customer satisfaction and good will. The end result is a product platform design process that will improve response to customer requests, reduce design cost, and improve time to market for companies that make small production runs of highly customized products.
\end{abstract}

Keywords: Product families, product platforms, customization

\section{INTRODUCTION}

It is difficult to maintain commonality and economies of scale in products with strict customer design requirements that may vary greatly from contract-to-contract or piece-to-piece. Often, these products are highly customized or possibly unique, which leads to high development and production costs that are difficult to predict and to long and uncertain production times. A manufacturer of these products may eventually develop a quasi-standard product line, but since the line is designed one custom product at a time, the full spectrum of product offerings is rarely reviewed to ensure that it is optimal for the business (Mather, 1995). Focusing on custom products can result in "a failure to embrace commonality, compatibility, or standardization" (Meyer and Lehnerd, 1997), leading to a proliferation of products and parts with increasing costs and overhead. The failure potential is even greater for highly customized product lines and of utmost importance to small manufacturers that do not have the "deep pockets" and "financial float" that is available in larger companies (Maupin and Stauffer, 2000).

Product families have been successfully employed by companies such as Sony (Sanderson and Uzumeri, 1997), Black \& Decker (Meyer and Lehnerd, 1997), and Lutron (Pessina and Renner, 1998) to address the challenge of providing variety for the marketplace while maintaining commonality between products. For instance, Airbus is currently enjoying a competitive advantage over Boeing due to improved commonality, particularly in the cockpit. The A330 cockpit is

\footnotetext{
1 Graduate Research Assistant.

2* Assistant Professor, Member ASME, and Corresponding Author, 329 Leonhard Building, Penn State University, University Park, PA 16802. Email: tws8@psu.edu. Phone/fax: (814) 863-7136/4745.
} 
common to all other Airbus types while Boeing's 767-400 cockpit is common only with the 757. This has enabled the A330-200, a less efficient "shrink" of a larger aircraft, to outsell Boeing's 767-400ER, a more efficient "stretch" design of a smaller aircraft, last year (Aboulafia, 2000).

A product family is a group of related products that share common features, components, and subsystems; yet satisfy a variety of market niches. The set of common parameters, features, or components that remain constant from product to product within a given product family is referred to as a product platform. The product platform provides the basis for the product family, which is derived through the addition, substitution, or exclusion of one or more modules from the platform (see, e.g., Dahmus, et al., 2000; Gonzalez-Zugasti and Otto, 2000; Martin and Ishii, 2000; Ulrich, 1995; Zamirowksi and Otto, 1999) or by scaling the platform in one or more dimensions (see, e.g., Messac, et al., 2000; Nayak, et al., 2000; Simpson, et al., 2001).

We have found two basic approaches to product family design in the literature.

(1) Top-down approach: a company strategically manages and develops a family of products based on a product platform and its derivatives. For instance, Sony strategically manages the development of their Walkman ${ }^{\circledR}$ products using carefully designed product platforms and derivatives Sanderson and Uzumeri, 1997).

(2) Bottom-up approach: a company redesigns or consolidates a group of distinct products to standardize components to improve economies of scale. For instance, after working with customers to individually develop 100+ lighting control products, Lutron redesigns its product line around 15-20 standard components that can be configured into the same 100+ models from which customers could initially choose Pessina and Renner, 1998).

The focus in this paper is on extending our previous work in the former to address the latter. In particular, the Product Platform Concept Exploration Method (PPCEM) introduced in (Simpson, et al., 1999) was developed as a top-down approach for product platform and product family design. In this paper, we employ the PPCEM in a bottom-up approach to leverage redesign effort over a highly customized product line like heavy industrial equipment used for material processing, manufacturing, or power production. Custom equipment is also prevalent in the highly regulated nuclear power industry. For instance, valves are common components in nuclear plant piping systems, and many of them are custom built to respond to specific design and accident scenarios. When designing a valve to meet custom requirements, it is typical for the company to simply modify a previously built design. This process can be time consuming and expensive because the capability of the previous design to handle the new requirements is not precisely known, and a complete review is necessary to determine required modifications and cost. Moreover, product line consistency and control can be lost in the process.
We assert that a carefully designed product platform can help reduce the design and review effort and shorten product lead-time. Consequently, our goal in this paper is to use the PPCEM to define a family of valve yoke cross-sections that envelops expected customer requirements. In the next section a brief overview of the PPCEM is given. In Section 3, we demonstrate how the PPCEM can be used to produce a set of valve yoke cross-sections that can be leveraged across a range of popular valve sizes, types, and pressure classes, thereby reducing part count while maintaining sufficient product variety for the market. Concluding remarks are then offered in Section 4.

\section{NOMENCLATURE}

$a \quad=$ Yoke Cross-Section Dimension

$A_{C S}=$ Yoke Leg Cross-Section Area

$b \quad=$ Yoke Cross-Section Dimension

$c \quad=$ Yoke Cross-Section Dimension

$D \quad=$ Valve Disc Sealing Diameter

$F \quad=$ Objective Function Value

$F_{C S} \quad=$ Yoke Leg Cross-Section Footprint

$f_{M I N}=$ Minimum Allowed Yoke Leg Natural Frequency

$f_{S} \quad=$ Stem Factor

$g \quad=$ Static Seismic Load Coefficient

$H_{A} \quad=$ Actuator Horizontal c.g.

$L_{A} \quad=$ Actuator Vertical c.g.

$L_{Y} \quad=$ Yoke Height

$P \quad=$ Valve Pressure Rating

$Q_{A} \quad=$ Actuator Induced Torque

$S_{Y} \quad=$ Yoke Leg Allowable Stress

$T_{A} \quad=$ Actuator Induced Thrust

$W_{A} \quad=$ Actuator Weight

$W_{Y} \quad=$ Yoke Weight

$W_{F} \quad=$ Yoke Flange Weight

\section{OVERVIEW OF THE PRODUCT PLATFORM CONCEPT EXPLORATION METHOD}

In (Simpson, et al., 1999) the Product Platform Concept Exploration Method (PPCEM) is introduced, which provides the foundation for this work. The input to the PPCEM is the overall design requirements, and the output is the product platform and resulting product family. The PPCEM consists of five steps that prescribe how to formulate the product family design problem and describe how to solve it; the actual implementation of each step is likely to vary from problem to problem. A brief overview of each step follows.

Step 1: Create the Market Segmentation Grid - This step involves mapping the overall design requirements into an appropriate market segmentation grid (Meyer, 1997), as shown in Figure 1. The grid allows for identification of potential leveraging opportunities for the product platform to effectively satisfy a variety of market segments. As shown in Figure 1, horizontal, vertical, and beachhead approaches can enable 
effective platform leveraging both within and across different market segments.
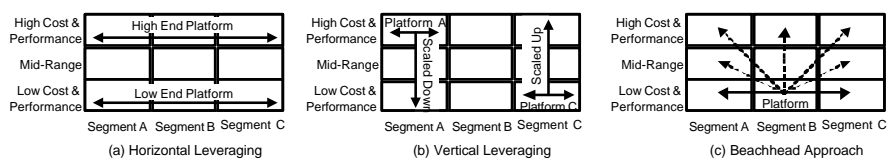

Figure 1. Market Segmentation Grid and Platform Leveraging Strategies (Meyer, 1997)

Step 2: Classify the Factors and Ranges - This step involves mapping the overall design requirements and market segmentation grid into appropriate factors and identifying corresponding ranges for each scaling variable. Scaling variables are the design variables that vary from product to product within a given product family and are used to "stretch" or "shrink" members of the product family to instantiate their individual performance. Scaling variables facilitate the platform leveraging strategies identified in Step 1.

Step 3: Build and Validate Metamodels - This step includes modeling computationally expensive computer simulation codes using computationally inexpensive metamodels (e.g., response surfaces, kriging (Simpson, et al., 1997)). In the valve yoke design example presented in the next section, this step is omitted since the valve manufacturer uses a simple Microsoft Excel spreadsheet template to perform analyses to demonstrate and document compliance with custom requirements. The template contains numerous programs written in Microsoft Visual Basic that automate the analysis process. A detailed presentation of one such program involving valve flange design is presented in (Farrell, 1999).

Step 4: Aggregate Product Family and Product Platform Specifications - This step includes formulating the product platform and product family design problem based on the market segmentation grid, the factors and ranges, and the overall design requirements.

Step 5: Develop the Product Platform and Product Family Solve the product family design problem formulated in Step 4 to obtain the product platform and corresponding family of products, which best satisfies the overall design requirements. For the valve yoke design example, we formulate an optimization problem and employ a Visual Basic macro program in an Excel spreadsheet to minimize a function based on the yoke leg crosssection. The problem involves continuous non-linear functions, and the generalized reduced gradient (GRG) algorithm is employed, which was adapted from (Belegundu and Chandrupatla, 1999). The GRG method requires function derivatives, and the implemented algorithm uses forward difference techniques to determine them. Other algorithms could be used to perform the optimization of the non-linear problem; for instance, a simulated annealing was utilized in (Farrell, 1999) to optimize the bolted pressurized flange designs, which involves a similar non-linear optimization formulation.
To demonstrate the application of the PPCEM, in the next section we describe the creation of a product platform consisting of modular, scalable valve yoke cross-sections for use in a wide range of valves of various sizes and types. First, we show the construction of a market segmentation grid to identify a suitable market segment in which to target the valve yoke redesign. Next, we establish a set of design parameters from existing design data that reasonably meets the requirements of the targeted segment to provide a benchmark for the redesigned yoke cross-section platforms. We then design the new yoke cross-section product platform and resulting family of products and discuss how well it satisfies the requirements for the target market segment.

\section{VALVE YOKE PRODUCT PLATFORM DESIGN EXAMPLE}

\subsection{Yoke Design Parameters}

Before presenting the development of the yoke product platforms, the yoke design procedure employed by the valve manufacture is reviewed.

In the utility industry, the valve yoke is a component that often requires modification to meet custom requirements. In its actuator-supporting role, it must be designed for strength (stress) and adequate rigidity (natural frequency). The actuator imposes loading on the yoke as it raises and lowers a disc or plug that controls flow of the process fluid, which is either low or high pressure water or high pressure steam in a power plant. Typically, the actuator is either motor, pneumatic, hydraulic, or manually operated. Power actuators can be very heavy, and inertia effects (e.g., earthquake or general plant vibrations) can result in significant additional loading on the yoke; in most cases, this dynamic loading can be related to natural frequency.

The valve manufacturer has developed standard analysis procedures that determine yoke stress due to inertial and external loading, and transverse natural frequency. The pertinent procedures employed in this work are summarized in the Appendix and are embodied in an Excel spreadsheet template that contains numerous macros written in Visual Basic in an Excel spreadsheet to automate the analysis process. The procedures model the valve superstructure with a number of sections, and each section has an associated length, crosssection, and lumped weight distribution as shown in the valve superstructure examples in Figure 2 and Figure 3. Typically, one section models the yoke, which provides mounting for the actuator. These standard analysis procedures also include the determination of yoke cross-section properties. 


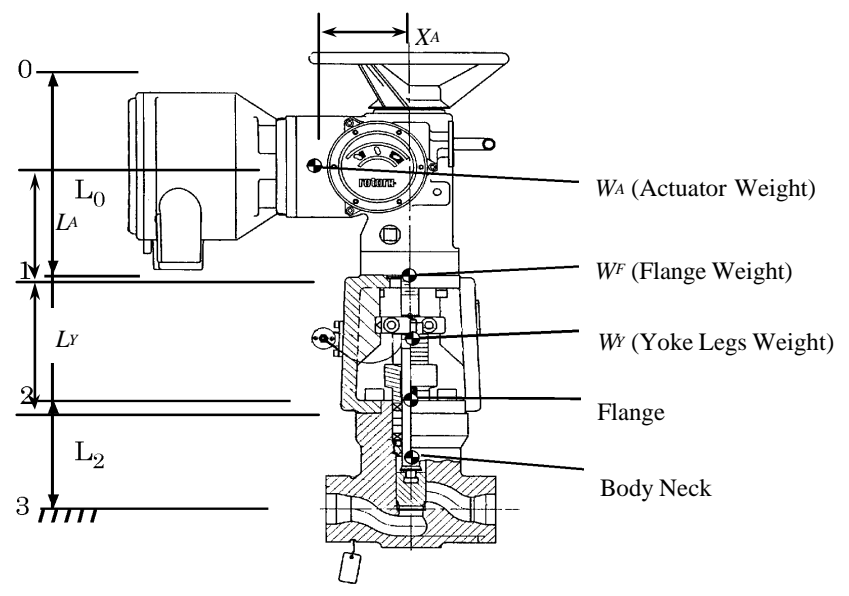

Figure 2. Typical Motor Operated Globe Valve

For this study, two of the most common cross-sections produced by the valve manufacturer provide the foundation for designing the product platform. In the Appendix, we show the shapes, define dimensions, give yoke cross-section code numbers, and present the procedure for calculating crosssection properties. These cross-sections include two legs, and the section properties (i.e., area, moment of inertia, and centroid) are defined for only one leg. The moment of inertia is defined for two axes: the beam mode axis (B-B) that is used when considering beam-type bending of the yoke legs, and the frame mode axis (F-F) that is used when considering frame-type bending.

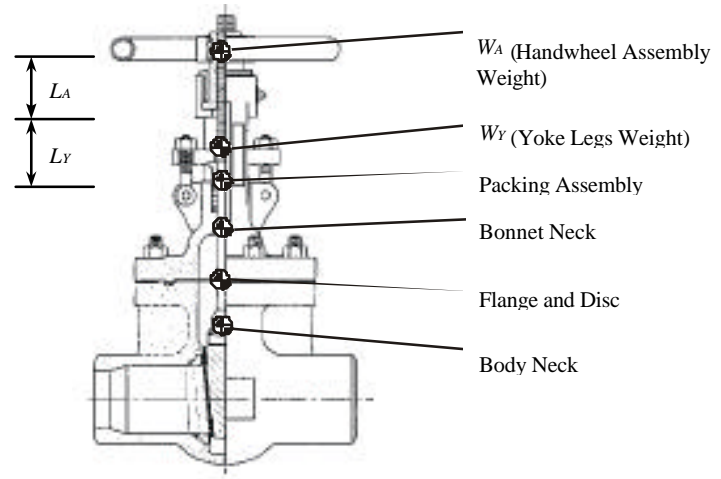

\section{Figure 3. Typical Manual Operated Flex Wedge Gate Valve}

A yoke is typically cast and constructed of carbon, stainless or low alloy steel as they must be strong enough to support forces from several sources. The yoke experiences actuator-induced thrust and possibly torque that is required to exercise the valve disc or plug and modulate the process fluid flow. In addition, dead weight and dynamic inertial forces due to seismic and hydrodynamic loading are possible inputs.
Finally, valves are classified by functional type, the size of the connecting piping, and the intended working pressure of the process fluid. As discussed in the next section, these characteristics also define the market segment(s) to which each valve is targeted.

\subsection{The Market Segmentation Grid}

When applying the bottom-up approach to product family design, a market segmentation grid is established from the existing product line, and the grid should reflect the company's overall target market. The market is typically well known, and the grid segmentation should contain the product types, grades, sizes, or other designations that are typically already established. If the target market or product is not yet established, a top-down design approach to platform design, rather than redesign, should be considered.

As the example in this paper, we develop a market segmentation grid for nuclear grade valves, and we limit the segmentation grid to valve types that have similar actuator mounting yoke structures. The valve types include double disc gate, flexible wedge gate, and globe. The valves have a basic size designation, which is defined by the connecting piping nominal diameter that ranges from one inch to twenty-four inches. They are also graded by pressure class, which defines allowed working pressure that ranges from class 150 to class 4500; currently however, the need for extremely high pressure class valves in nuclear power plants is rare, and this study does not consider classes above 1500. Thus, the basic market segmentation grid is defined by 3 attributes: (1) valve type, (2) pressure rating, and (3) size. Additional attributes could be added to the grid to address market demand or specific customer requirements, or the grid could be further segmented based on performance-cost grades as demonstrated in Section 3.3.

For highly customized products, it can be difficult to establish the market niches and the design requirements with certainty, as future demand and requirements can be markedly different from the past. Despite the uncertainty, we propose using data from previously manufactured custom products as a basis for creating the market segmentation grid. Although the resulting platforms may not meet all future requests, we believe we can envelop a significant percentage of them while providing a basis for future platform development and customization.

To identify potential valve market niches, we examine design data from the numerous Microsoft Excel spreadsheets used by the manufacturer to perform customer required design calculations between the years 1994 and 1999. Pertinent data was extracted from the spreadsheets and incorporated into a Microsoft Access Database. The database was queried to yield the valve quantities summarized in Table 1 as a function of pressure class, size, and type. Although each data record can correspond to one or several manufactured valves, they are of identical design, and each record is counted only once when tallying, which is assumed sufficient for estimating customer 
demand. In the table, a missing pressure class or a blank quantity indicates that no valves were analyzed for these sizes within the referenced time frame; the manufacturer would willingly produce valves for these missing categories as requested. The table gives a sufficient overview of the developed market segmentation grid. However, performance grades due to customer design requirements have yet to be addressed, three performance tiers are proposed in Section 3.3, and these are considered part of the market segmentation grid.

Table 1. Valve Quantity Grouped by Pressure Class, Size and Type

\begin{tabular}{|c|c|c|c|c|}
\hline $\begin{array}{c}\text { Pressure } \\
\text { Class }\end{array}$ & $\begin{array}{c}\text { Valve } \\
\text { Size } \\
\text { [inch] }\end{array}$ & $\begin{array}{c}\text { Double } \\
\text { Disc Gate } \\
\text { Count }\end{array}$ & $\begin{array}{c}\text { Flex } \\
\text { Wedge } \\
\text { Gate } \\
\text { Count }\end{array}$ & $\begin{array}{l}\text { Globe } \\
\text { Count }\end{array}$ \\
\hline \multirow[t]{12}{*}{150} & 1 & & & 3 \\
\hline & 2 & 6 & 2 & 3 \\
\hline & 3 & 1 & 4 & 9 \\
\hline & 4 & & 2 & ــ \\
\hline & 6 & 2 & 8 & 2 \\
\hline & 8 & 5 & 0 & 5 \\
\hline & 10 & 1 & 8 & 2 \\
\hline & 12 & & 1 & \\
\hline & 14 & 1 & 2 & \\
\hline & 16 & & 3 & \\
\hline & 20 & & 1 & \\
\hline & 24 & & 2 & \\
\hline \multirow{9}{*}{300} & 3 & 1 & 1 & 1 \\
\hline & 4 & 2 & 2 & 2 \\
\hline & 6 & & 1 & 1 \\
\hline & 8 & & 2 & \\
\hline & 10 & 2 & 3 & 1 \\
\hline & 12 & & & 1 \\
\hline & 16 & & 1 & \\
\hline & 18 & & 7 & 4 \\
\hline & 20 & & 1 & \\
\hline \multirow[t]{7}{*}{600} & 1 & 2 & & 4 \\
\hline & 2 & 3 & - & 9 \\
\hline & 3 & & 1 & 6 \\
\hline & 4 & 2 & 2 & 1 \\
\hline & 6 & 1 & 3 & \\
\hline & 8 & 7 & & \\
\hline & 10 & & 1 & 1 \\
\hline \multirow[t]{10}{*}{900} & 2 & 2 & & 1 \\
\hline & 3 & 8 & 5 & 7 \\
\hline & 4 & 1 & 14 & 7 \\
\hline & 6 & 6 & 6 & 6 \\
\hline & 8 & 1 & & \\
\hline & 10 & 5 & 3 & 1 \\
\hline & 12 & 1 & 1 & 1 \\
\hline & 14 & & 1 & 1 \\
\hline & 20 & 1 & 1 & \\
\hline & 24 & & 2 & \\
\hline \multirow[t]{6}{*}{1500} & 1 & & & 11 \\
\hline & 2 & 7 & 1 & 10 \\
\hline & 3 & & 2 & 1 \\
\hline & 4 & & 1 & 1 \\
\hline & 8 & 1 & & \\
\hline & 12 & & & 2 \\
\hline
\end{tabular}

\subsection{Product Platform Leveraging Strategy}

As stated in Section 2, the resulting market segmentation grid helps identify potential platform leveraging strategies. We use the valve tally per Table 1 , which adequately describes the basic developed grid, to identify subsets of the company's product line where yoke cross-section leveraging can potentially provide the largest cost savings. We begin with the premise that platform leveraging can have the greatest impact where past customer demand was highest, and proceed by defining a subset of the complete market segmentation grid where leveraging has the greatest cost savings potential.

Valve sizes two inches and smaller are not included as part of the subset because the manufacturer already implements leveraging across these sizes. With the small sizes excluded, it is concluded that the size range of three to ten inches provides the greatest potential cost savings.

In addition to demand, engineering technicalities associated with potential platform leveraging strategies must be considered. Although the three valve types considered require similar actuator mounting capabilities, the basic operating characteristics of the two gate valve types are similar and warrant leveraging, whereas the globe valve characteristics are significantly different. Therefore, the resulting subset consists of the two gate valve types in sizes ranging from three inches to ten inches. The valve quantities associated with the developed subset are highlighted in gray in Table 1.

In addition to leveraging across the gate valve types, leveraging across pressure classes and valve size can be implemented. Although many yoke platforms could be designed to envelop the subset, only two examples are considered. One platform leverages across 3 and 4 inch gate valve sizes in the 900 pressure class. The other platform leverages across 6 and 8 inch gate valve sizes in the 150 and 300 pressure classes. Thus, we achieve platform leveraging in three ways: (1) across valve types, (2) across valve sizes, and (3) across valve pressure classes. We classify this as horizontal leveraging because valve type, size, and pressure class are considered segments of the segmentation grid.

The diversity of customer requirements suggests that the introduction of valve performance grades will further improve the ability to efficiently target the placement of valve yoke platforms. Therefore, we propose a three-tiered strategy as shown in Figure 4. The bottom 'manual' tier addresses manually operated valves that are relatively lightweight and have rather standard performance requirements. The second 'normal duty' grade tier addresses valves that require heavy electric motor actuators and nominal performance requirements. The third 'heavy duty' grade tier address motor operated valves with more demanding performance requirements such as high seismic loading or high required minimum natural frequency. 


\begin{tabular}{|c|}
\hline Heavy Duty Tier \\
\hline Normal Duty Tier \\
\hline Manual Tier \\
\hline
\end{tabular}

Figure 4. Performance Grade Tiers

We address only the 'normal duty' grade tier in the example; hence, no vertical leveraging across tiers is attempted. The quantities listed in Table 1 include both manual and motor operated valve designs, and the manual designs are removed from consideration when aggregating platform specifications. The developed 'normal duty' grade tier market segmentation grid subset and the two proposed platforms are shown in Figure 5. The figure gives the number of design instances that fit into the platform space, and the corresponding quantity listed in Table 1, which includes all tiers (manual and motor actuated designs).

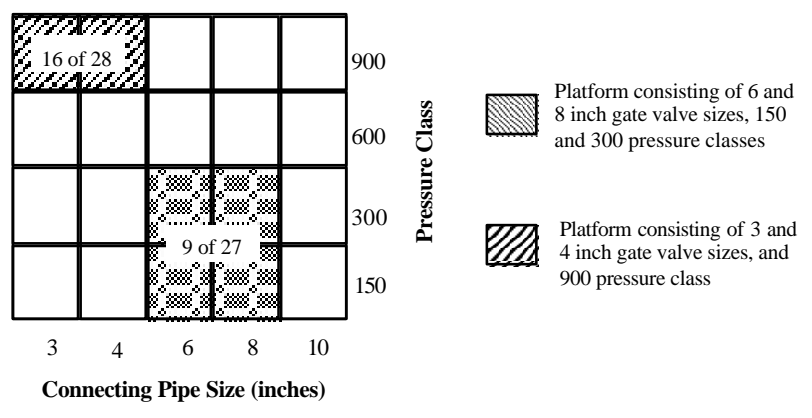

\section{Figure 5. Market Segmentation Grid Subset Showing Developed Normal Duty Grade Tier Platforms and Involved Design Quantities as a Subset of the Original Tally}

Despite the limited appearance of the horizontal leveraging, we believe the proposed yoke cross-section leveraging strategy is a good compromise between cost savings and performance based on past engineering experience. If the leveraging is too aggressive, performance inefficiencies could dominate, resulting in decreased customer satisfaction. For the yoke design for instance, too much leveraging could result in the application of a large and heavy yoke on a relatively small valve. The leveraging strategy subjectively considers the compromise between cost savings and performance, but detailed platform parameters that achieve the desired performance are yet to be established. The platforms are designed using aggregate data from the available design data in the next section.

\subsection{Classify Factors and Ranges}

Design inputs and constraints for the yoke cross sections are listed in Table 2. The values for actuator weight (WA) and centers of gravity (LA and HA) are the maximum for the motor actuated valves from the calculation database. The effective seismic load $(\mathrm{g})$ is the average from the database and acts as a static load coefficient on extended structure weights. The yoke length (LY) can vary from valve to valve, and the employed length equals the maximum from the available data, which is the most severe condition with respect to stress and natural frequency. The yoke stress limit (SY) equals the minimum specified yield strength (ASME Code, 2000) at 700 degrees Fahrenheit for stainless steel material specification SA351CF8M, which is the known lower limit of strength for company standard materials. Customer specifications typically require valve extended structure natural frequency to be below $33 \mathrm{~Hz}$, and a yoke only limit of $40 \mathrm{~Hz}$ (fMIN) is assumed adequate as the yoke is typically the most flexible portion of the extended structure. The database instances associated with the platforms utilize both defined cross-section types, and although the code 101 cross-section is the most commonly used, we select a different type for each platform for contrast. The limiting dimensions on the cross-section are imposed to avoid interference with other valve parts and allow space for valve assembly and maintenance. 
Table 2. Product Platform Constraints and Normal Grade Loading

\begin{tabular}{|l|c|c|c|}
\hline $\begin{array}{l}\text { Horizontal } \\
\text { Leveraging }\end{array}$ & Units & $\begin{array}{c}\text { 3 inch \& 4 inch, } \\
\text { 900 Pressure } \\
\text { Class }\end{array}$ & $\begin{array}{c}\text { 6 Inch \& 8 Inch, } \\
\text { 150 \& 300 } \\
\text { Pressure Class }\end{array}$ \\
\hline \hline $\begin{array}{l}\text { Actuator Weight, } \\
W_{A}\end{array}$ & $\mathrm{~kg}$ & 170.2 & 213.3 \\
\hline $\begin{array}{l}\text { Actuator Vertical } \\
\text { c.g., } L_{A}\end{array}$ & $\mathrm{~mm}$ & 165.1 & 165.1 \\
\hline $\begin{array}{l}\text { Actuator } \\
\text { Horizontal c.g., } \\
H_{A}\end{array}$ & $\mathrm{~mm}$ & 180.3 & 142.7 \\
\hline $\begin{array}{l}\text { Effective Seismic } \\
\text { Load, g }\end{array}$ & $\mathrm{g}$ 's & 7.4 & 7.7 \\
\hline $\begin{array}{l}\text { Yoke Leg Length, } \\
L_{Y}\end{array}$ & $\mathrm{~mm}$ & 257.3 & 336.6 \\
\hline Stress Limit, $S_{Y}$ & $\mathrm{MPa}$ & 124.8 & 124.8 \\
\hline $\begin{array}{l}\text { Frequency Limit, } \\
f_{\text {MIN }}\end{array}$ & $\mathrm{Hz}$ & 40 & 40 \\
\hline $\begin{array}{l}\text { Cross-Section } \\
\text { Code (see } \\
\text { Appendix) }\end{array}$ & & 5 & 101 \\
\hline $\begin{array}{l}\text { Limiting } \\
\text { Dimension, } a\end{array}$ & $\mathrm{~mm}$ & $\mathrm{~N} / \mathrm{A}$ & $63.5 \mathrm{~min}$ \\
\hline $\begin{array}{l}\text { Limiting } \\
\text { Dimension, } c\end{array}$ & $\mathrm{~mm} / \mathrm{rad}$ & $52.4 \mathrm{~min}$. & $0.8727 \mathrm{max}$. \\
\hline
\end{tabular}

A major yoke load is actuator-induced thrust and torque, and Eqn. 1 gives a general relation that conservatively approximates what is required to close a typical valve against differential pressure.

$$
\begin{gathered}
T_{A}=\frac{\pi}{4}(D)^{2}(2.5 P)(.5) \\
Q_{A}=f_{S} T_{A}
\end{gathered}
$$

Variables include actuator induced thrust (TA), actuator induced torque $(\mathrm{QA})$, pressure class $(\mathrm{P})$, valve disc sealing diameter(D), and stem factor (f). The basic valve size is used to approximate the sealing diameter (D). The ' 2.5 ' factor approximately converts pressure class to the maximum possible pressure rating, and the ' 0.5 ' factor (valve factor) accounts for frictional drag between the valve disc and seats during closing and sealing. A stem factor (f) of $0.011 \mathrm{ft}$ was used in all cases to approximate the conversion of torque to thrust that is accomplished by ACME power threads (ASME, 1997). These loading constraints and design inputs provide the basis for the developed yoke platforms as discussed in the next section.

\subsection{Aggregate Product Family and Product Platform Specifications}

The yoke cross-section platforms result from the solution of an optimization problem whose objective is to minimize the size of the yoke legs while satisfying loading and size constraints. Toward this end, the objective function $(\mathrm{F})$, given by Eqn. 2, combines the cross-section area (ACS), the 'footprint' (FCS), and the yoke length (LY), and equals the sum of a yoke leg's metal volume and footprint volume. The footprint defines a rectangular area that encloses an entire leg section, and equations for ACS and FCS and a depiction of the footprint are included in the Appendix.

$$
F=\left(A_{C S}+F_{C S}\right) L_{Y}
$$

The design variables are the yoke cross-section parameters ( $a, b$, and $\mathrm{c}$ as noted in Appendix), and the objective function is subject to the following constraints:

(1) the limiting values for the design variables a and c as given in Table 2; and

(2) the stress and frequency limits per Table 2.

Stress and frequency are determined using the procedures outlined in the Appendix and require actuator weight and c.g., the effective seismic load, the actuator induced thrust and torque per Equation (1), and the yoke leg length as static input. The analysis procedures also require cross-section properties that are functions of the design variables and are determined per the equations listed in the Appendix.

\subsection{Development of the Yoke Product Platform and Corresponding Product Family}

Both the objective and constraints are continuous nonlinear functions, and the GRG algorithm mentioned in Section 2 is used to obtain solutions to the developed optimization problem. The optimal objective, corresponding design variables and values of constraints are given for the two platforms in Table 3. The three imposed limiting dimensions for the design variables a and $\mathrm{c}$ are active, and among the four stress and frequency constraints, only a single stress constraint is active for each case. A comparison of these platforms with existing designs is offered in the next section to evaluate the tradeoff between commonality and individual performance within the yoke designs. 
Table 3. Yoke Product Platforms Developed for the Market Segments

\begin{tabular}{|l|c|c|c|}
\hline $\begin{array}{c}\text { Horizontal } \\
\text { Leveraging }\end{array}$ & Units & $\begin{array}{c}\text { 3 inch \& 4 inch, } \\
\text { 900 Pressure } \\
\text { Class }\end{array}$ & $\begin{array}{c}\text { 6 Inch \& 8 Inch, } \\
\mathbf{1 5 0} \text { \& 300 } \\
\text { Pressure Class }\end{array}$ \\
\hline \hline Objective, $F$ & $\mathrm{~cm}^{3}$ & 2,692 & 10,964 \\
\hline $\begin{array}{l}\text { Cross- } \\
\text { Section Code }\end{array}$ & & 5 & 101 \\
\hline Dimension $a$ & $\mathrm{Mm}$ & 82.91 & $63.5^{\mathrm{a}}$ \\
\hline Dimension $b$ & $\mathrm{Mm}$ & 36.93 & 31.34 \\
\hline Dimension $c$ & $\mathrm{~mm} / \mathrm{rad}$ & $52.4^{\mathrm{a}}$ & $.8727^{\mathrm{a}}$ \\
\hline $\begin{array}{l}\text { Frame Mode } \\
\text { Stress }\end{array}$ & $\mathrm{MPa}$ & 117.2 & $124.8^{\mathrm{a}}$ \\
\hline $\begin{array}{l}\text { Beam Mode } \\
\text { Stress }\end{array}$ & $\mathrm{MPa}$ & $124.8^{\mathrm{a}}$ & 93.91 \\
\hline $\begin{array}{l}\text { Frame Mode } \\
\text { Frequency }\end{array}$ & $\mathrm{Hz}$ & 97.63 & 64.99 \\
\hline $\begin{array}{l}\text { Beam Mode } \\
\text { Frequency }\end{array}$ & $\mathrm{Hz}$ & 49.75 & 78.25 \\
\hline
\end{tabular}

${ }^{a}$ Active constraints at optimum

\subsection{Comparison with Existing Designs}

Table 4 and Table 5 give results of assessments that test the effectiveness of applying the platforms to the applicable 'normal duty' grade tier valve design. Since these designs are individually customized, they can differ from one another in several ways: (1) the cross-section type and dimensions, (2) yoke height, (3) the actuator weight, c.g., and operating loads, (4) seismic loading, and (5) yoke material type. One part of the assessment involves comparing the platform cross-sections to each individual design, verifying that all constraints are satisfied, and determining the objective function value. The other part of the assessment involves performing the GRG optimization for each design individually, and then comparing resulting objective function values with the platform-based products. A negative difference in the objective function value relative to the platform design indicates that the optimized design performs better than the platform-based design, and a positive difference indicates that the individual design actually performs worse.
Table 4. Three \& Four Inch, 900 Pressure Class Valve Yoke Platform Instantiations

\begin{tabular}{|c|c|c|c|c|c|c|c|c|c|}
\hline & & \multicolumn{6}{|c|}{ OPTIMIZED INSTANCES } & \multirow[b]{2}{*}{$\begin{array}{l}\text { Platform } \\
\text { Objective }\end{array}$} & \multirow[b]{2}{*}{$\begin{array}{l}\text { Difference } \\
\text { from } \\
\text { Platform }\end{array}$} \\
\hline $\begin{array}{l}\text { Instance } \\
\text { I.D. or } \\
\text { Platform }\end{array}$ & $\begin{array}{c}\text { Valve } \\
\text { Size }\end{array}$ & $\begin{array}{c}\text { Cross- } \\
\text { Section } \\
\text { Code } \\
\end{array}$ & $a$ & $b$ & $c$ & $L Y$ & $\begin{array}{l}\text { Instance } \\
\text { Obiective }\end{array}$ & & \\
\hline & [in] & & {$[\mathrm{mml}$} & {$[\mathrm{mml}$} & & {$[\mathrm{mml}$} & {$\left[\mathrm{cm}^{3}\right]$} & {$\left[\mathrm{cm}^{3}\right]$} & \\
\hline Platform & & 5 & 8001 & 36.03 & $5240 \mathrm{~mm}$ & 2573 & 2602 & 2602 & 0 \\
\hline R99078 & 3 & 5 & 73.63 & 1862 & $58.75 \mathrm{~mm}$ & 2286 & 1616 & 2391 & $-32 \%$ \\
\hline R99077 & 4 & 5 & 70.36 & 15.44 & $50.80 \mathrm{~mm}$ & 1270 & 730 & 1.329 & $-45 \%$ \\
\hline R98091 & 4 & 101 & 9368 & 6.452 & $8727 \mathrm{rad}$ & 2032 & 6.624 & 2126 & $211 \%$ \\
\hline $\mathrm{R} 98.075$ & 4 & 5 & 55.91 & 21.23 & $50.88 \mathrm{~mm}$ & 171.5 & 909 & 1.794 & $-49 \%$ \\
\hline Dos041 & 3 & 101 & 5001 & 1317 & $1047 \mathrm{rad}$ & 2324 & 3200 & 2442 & $35 \%$ \\
\hline R97094 & 4 & 101 & 7303 & 1283 & $902 \mathrm{rad}$ & 2350 & 5873 & 2459 & $139 \%$ \\
\hline R97.024 & 4 & 101 & 73.03 & 13.14 & $902 \mathrm{rad}$ & 235.0 & 5.924 & 2.459 & $141 \%$ \\
\hline 807023 & 4 & 101 & 7303 & 1223 & $902 \mathrm{rad}$ & 2350 & 5774 & 2450 & $135 \%$ \\
\hline $\mathrm{R} 97022$ & 4 & 101 & 7303 & 1590 & $839 \mathrm{rad}$ & 2350 & 6.343 & 2.459 & $158 \%$ \\
\hline R97003 & 3 & 101 & 73.03 & 8.839 & $902 \mathrm{rad}$ & 2477 & 5.519 & 2.592 & $113 \%$ \\
\hline B.66_112 & 3 & 101 & 7303 & 8087 & $902 \mathrm{rad}$ & 2350 & 5398 & 2450 & $108 \%$ \\
\hline B95.145 & 3 & 101 & 88.90 & 8.664 & $7854 \mathrm{rad}$ & 2413 & 7521 & 2.525 & $198 \%$ \\
\hline R95.084 & 4 & 101 & 73.03 & 1160 & $9001 \mathrm{rad}$ & 2350 & 5.671 & 2.459 & $131 \%$ \\
\hline $\mathrm{R} 95020$ & 4 & 5 & 9700 & 1871 & $52.40 \mathrm{~mm}$ & 171.5 & 1.493 & 1794 & $-17 \%$ \\
\hline R95.005 & 3 & 101 & 1000 & 7.170 & $7854 \mathrm{rad}$ & 257.3 & 9.588 & 2.692 & $256 \%$ \\
\hline R94.113 & 3 & 101 & 50.80 & 22.60 & $5231 \mathrm{rad}$ & 1477 & 2715 & 1.545 & $76 \%$ \\
\hline & & & & & ance Aver & & 4.687 & & \\
\hline
\end{tabular}

Table 5. Six \& Eight Inch, $150 \& 300$ Pressure Class Valve Yoke Platform Instantiations ${ }^{b}$

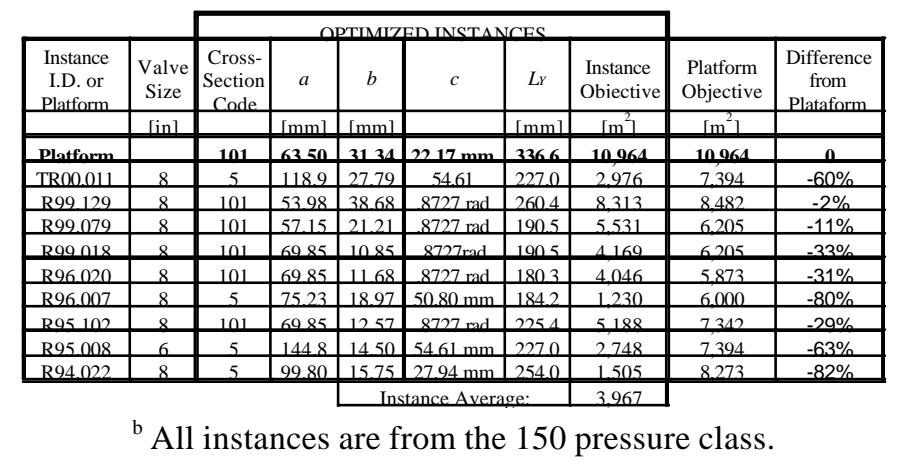

The platform-based designs shown in Table 4 compare well with the individual design instances; regrettably however, the designs for the platform per Table 5 are highly skewed toward 8inch class 150 designs. Although this does not invalidate the effectiveness of the valve family given in Table 5, it may indicate that its ability to target customer requests is not as certain as for the valve family listed in Table 4 .

Based on the data in Table 4 and Table 5, we conclude that the two yoke platforms meet or exceed the basic individual design requirements in all cases. The exceeding of requirements indicates excess capacity, or slack, in the design, and this is expected because of the proposed leveraging strategy. A surprising result from Table 4 is that the platform, which has the code 5 cross-section shape, actually performs better than those originally based on the code 101 cross-section. This may indicate that the code 5 cross-section is the better shape in general; however, as mentioned previously, implementation of a code 5 cross-section on an instance with a code 101 crosssection may not be cost effective.

For cases where the difference between the platform and instance objective is negative, the extreme difference is $-80 \%$ and the average difference is $-41 \%$. Assuming the objective 
difference roughly translates into weight difference, results indicate that in the worst case, the yoke leg weight for an implemented platform could be about twice that for an individually optimized design. Since the yoke leg weight is small relative to other parts of an extended structure (the actuator weight is the most significant), we believe that this is an acceptable tradeoff between platform commonality and individual valve performance. However, one goal of future platform modifications could be to reduce these statistics through more effective platform leveraging strategies.

When applying the yoke product platforms to the design instances, the yoke lengths are scaled to match the instance length, and it is necessary to make this scaling practical. Valve yokes are very typically manufactured from castings, each yoke requires a pattern, and the use of a modular architecture design for the yoke platform patterns would facilitate this scaling. A yoke platform pattern could consist of various end flanges for mounting to different valves and actuators, and various lengths of the platform cross-section, with the required yoke length consisting of one or more segments. Although pattern change pieces are commonly used in practice to reduce the need to construct and store multiple patterns, we believe that modular pattern designs, based on these yoke product platforms, could more effectively reduce pattern construction and minimize the number of existing patterns that must be stored. Consequently, significant storage and construction cost savings could be realized.

As mentioned in Section 3.4, design instances associated with a single platform employ a mix of the two cross-section types. This may indicate that a single modular yoke pattern may not easily fit all instances, and it may be cost effective to develop a second set of platforms with complementary crosssections. Therefore, it may be stated that we leverage across cross-section types in the examples, and it may be proper to further segment the developed market segmentation grid by cross-section type.

\section{CLOSING REMARKS}

Using the Product Platform Concept Exploration Method, we have designed two valve yoke cross-section product platforms for two targeted market segments that enable platform leveraging and improve commonality in the custom valve product. We demonstrate the leveraging of two cross-section platforms over twenty-five valve designs based on customer demand of current designs. The platforms also compare favorably to existing designs, and since future custom design requirements are not known, it is admittedly difficult to precisely assess the future potential of each platform. However, we believe that they would meet a significant percentage of future custom requirements, and the improvement in commonality and standardization would result in cost savings and reduced design lead-time over the conventional design approach.
Implementation of the yoke platforms also translates into improved quotation and lead times, and improved customer satisfaction and good will. The greatest potential for direct cost savings may be with the patterns required to manufacture yoke castings, as the proposed modular architecture for pattern construction would significantly reduce the need for new yoke patterns. The construction or modification of a pattern typically costs at least $\$ 1500$, and implementation of the yoke platforms would realize this as a direct saving multiple times.

This study of yoke product platforms is part of ongoing research at improving product line standardization through effectively designed product platforms. We seek to develop a method to redesign product platforms that can address a majority of current and future custom design requirements, reduce design and construction cost, and improve time-tomarket. As part of this strategy, we plan to develop analytical models to quantify these cost savings and simplify the process of mapping existing products into a market segmentation grid (as demonstrated in Section 3.2) to reduce the amount of product-specific knowledge required. Furthermore, enabling this method within a web-based framework would allow sales engineers, for instance, to provide prompt pricing and delivery quotations that answer customer's custom requests.

\section{ACKNOWLEDGMENTS}

The authors acknowledge with gratitude the cooperation of Flowserve Corporation in providing access to their design information.

\section{REFERENCES}

Aboulafia, R., 2000, "Airbus Pulls Closer to Boeing," Aerospace America, Vol. 38, No. 4, pp. 16-18.

ASME, 1997, "Power Threads," ASME ANSI B1.1, ASME, New York.

Belegundu, A. D. and Chandrupatla, T. R., 1999, Optimization Concepts and Applications in Engineering, Prentice Hall, Upper Saddle River, NJ.

Dahmus, J. B., Gonzalez-Zugasti, J. P. and Otto, K. N., 2000, September 10-13, "Modular Product Architecture," ASME 2000 Design Engineering Technical Conferences - Design Theory and Methodology Conference (DTM'00) (Allen, J. K., ed.), Baltimore, MD, ASME, Paper No. DETC2000/DTM-14565.

Ezekoye, L. I., 1978, “A Simplified Method for Calculating the Natural Frequency of Valve Superstructures", ASME, Paper No. 78-PVP-4.

Farrell, R. S., 1999, "Automatic Optimization of Valve Bolted Flanges," M.S. Thesis, Mechanical \& Nuclear Engineering, Penn State University, University Park, PA.

Gonzalez-Zugasti, J. P. and Otto, K. N., 2000, September 1013, "Modular Platform-Based Product Family Design," ASME 2000 Design Engineering Technical Conferences - Design Automation Conference (Renaud, J. E., ed.), Baltimore, MD, ASME, Paper No. DETC-2000/DAC-14238. 
Martin, M. V. and Ishii, K., 2000, September 10-13, "Design for Variety: A Methodology for Developing Product Platform Architectures," ASME Design Engineering Technical Conferences - Design for Manufacturing, Baltimore, MD, ASME, Paper No. DETC2000/DFM-14021.

Mather, H., 1995, October 22-27, "Product Variety -- Friend or Foe?" Proceedings of the 1995 38th American Production \& Inventory Control Society International Conference and Exhibition, Orlando, FL, APICS, pp. 378-381.

Maupin, A. J. and Stauffer, L. A., 2000, September 10-13, "A Design Tool to Help Small Manufacturers Reengineer a Product Family," ASME 2000 Design Engineering Technical Conferences - Design Theory and Methodology Conference (DTM'00) (Allen, J. K., ed.), Baltimore, MD, ASME, Paper No. DETC2000/DTM-14568.

Messac, A., Martinez, M. P. and Simpson, T. W., 2000, September 10-13, "Effective Product Family Design Using Physical Programming and the Product Platform Concept Exploration Method," Design Automation Conference (Renaud, J. E., ed.), Baltimore, MD, ASME, Paper No. DETC2000/DAC14252.

Meyer, M. H., 1997, "Revitalize Your Product Lines Through Continuous Platform Renewal," Research Technology Management, Vol. 40, No. 2, pp. 17-28.

Meyer, M. H. and Lehnerd, A. P., 1997, The Power of Product Platforms: Building Value and Cost Leadership, Free Press, New York.

Nayak, R. U., Chen, W. and Simpson, T. W., 2000, "A Variation-Based Method for Product Family Design," Engineering Optimization, in press.

Pessina, M. W. and Renner, J. R., 1998, "Mass Customization at Lutron Electronics - A Total Company Process," Agility \& Global Competition, Vol. 2, No. 2, pp. 50-57.

Roark, R.J., Young, W. C., 1989 "Formulas for Stress and Strain, 6th ed., McGraw-Hill, New York.

Sanderson, S. W. and Uzumeri, M., 1997, Managing Product Families, Irwin, Chicago, IL.

Simpson, T. W., Maier, J. R. A. and Mistree, F., 1999, September 12-15, "A Product Platform Concept Exploration Method for Product Family Design," Design Theory and Methodology - DTM'99, Las Vegas, Nevada, ASME, Paper No. DETC99/DTM-8761.

Simpson, T. W., Maier, J. R. A. and Mistree, F., 2000, "Product Platform Design: Method and Application," Research in Engineering Design, accepted for publication.

Simpson, T. W., Peplinski, J., Koch, P. N. and Allen, J. K., 1997, September 14-17, "On the Use of Statistics in Design and the Implications for Deterministic Computer Experiments," Design Theory and Methodology, Sacramento, CA, ASME, Paper No. DETC97/DTM-3881.

Ulrich, K., 1995, "The Role of Product Architecture in the Manufacturing Firm," Research Policy, Vol. 24, No. 3, pp. 419440.
Zamirowksi, E. J. and Otto, K. N., 1999, September 12-15, "Identifying Product Portfolio Architecture Modularity Using Function and Variety Heuristics," Design Theory and Methodology - DTM'99, Las Vegas, NV, ASME, Paper No. DETC99/DTM-8760.

\section{APPENDIX}

\section{A-1. Extended Structure Natural Frequency Analysis}

This is a procedure for determining natural frequencies of the valve extended structure due to bending .. The basic method is from ( Ezekoye, 1978), and employs Rayleigh's principal that states that the maximum kinetic energy must equal the maximum potential energy in order for the system to satisfy conservation of energy. The approach is to consider two models of the structure:

1. Cantilever beam mode that considers deflections normal to the yoke window plane.

2. Cantilever frame mode that considers deflections parallel to the yoke window plane.

Assumptions:

1. The piping and valve body is rigid, the base of the extended structure at the body crotch is rigidly fixed, and the extended structure components are rigidly connected.

2. Axial and pure shear displacements are negligible in comparison to those due to bending.

3. No structural damping exists.

4. Section weights are lumped at their centers of gravity.

Method:

Forces at Nodes: $\left(N=\right.$ Node \#): $F_{N}=W_{N} / 3+{ }_{1=1}^{N}\left(W_{1-1}+W^{\prime} 1\right)$

Moments at Nodes: $\mathrm{MN}_{\mathrm{N}}={ }_{\mathrm{K}=1}^{\mathrm{N}}\left\{\mathrm{S}_{\mathrm{K}}^{\mathrm{N}}\left(\mathrm{W}_{\mathrm{K}-1}+\mathrm{W}^{\prime} \mathrm{K}-1\right) \mathrm{LI}-1-\left(\mathrm{W}_{\mathrm{K}-1 \mathrm{LK}-1) / 2\}}\right\}\right.$

Slope \& Deflection at Nodes:

Beam Section:

$?_{N}($ Slope $)=F_{N} L_{N}^{2} /\left(2 P E_{N} I_{N}\right)+M_{N} L_{N}\left(P E_{N} I_{N}\right)$ $d_{N}($ Defll $)=F_{N} L_{N}^{3} /\left(3 P E_{N} I_{N}\right)+M_{N} L_{N}^{2} /\left(2 P E_{N} I_{N}\right)$

Frame Section:

$?_{N}($ Slope $)=M_{N} L_{N}\left(2 A_{N} E_{N} Y_{N}^{2}\right)$

$d_{N}($ Def'l $)=?_{N} L_{N} \sqrt{2}+F_{N} L_{N}^{3} /\left(24 E_{N} I_{N}\right)$

Max $N$

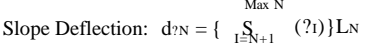

Section Node Deflection: $\quad \mathrm{dsN}_{\mathrm{N}}=\mathrm{dN}+\mathrm{d} \mathrm{N}$

Total Node Deflection: $\quad \mathrm{dTN}=\mathrm{R}_{\mathrm{R}} \mathrm{N}$ dSK

Natural Frequency:

$\left.f_{N} \stackrel{=}{=} g\left(S G_{N}\right) /\left(S G_{N}\right)\right]^{1 / 2} /(2 p)$

$C_{I N}=\left(W_{N}+W_{N}^{\prime}\right) d_{T N}$

$C_{2 N}=\left(W_{N}+W_{N}^{\prime}\right) d_{T N}$ 


\section{A-2. Stress Analysis of Yoke Legs}

Two models describe the static analysis techniques used for the beam and frame modes stress analysis respectively. The method agrees with several cases from (Roark and Young, 1989). A major assumption is that the yoke legs are much more flexible than the connections (or cross bars) at the nodes. This condition assures that maximum reaction forces in the legs are considered.

The analysis requires determination of reaction forces at both the top and bottom of the yoke legs. One source of reaction is static seismic inertia loading $(G)$ that acts on the actuator weight $\left(W_{A}\right)$, yoke top flange weight $\left(W_{F}\right)$, and the yoke legs weight $\left(W_{Y}\right)$. The other source is actuator induced thrust $\left(T_{A}\right)$ and torque ( $\left.Q_{A}\right)$. Reaction moment $(M)$, thrust $(T)$, Shear $(V)$, and Torque $(Q)$ are determined. Equation for the reactions follow which are based on classical force and moment balance. Figure 2 and Figure 3 from Section 3.1 give examples of pertinent valve extended structure parameters and shows the location of the weights described above an the actuator vertical c.g. $\left(L_{A}\right)$ and horizontal c.g. $\left(H_{A}\right)$, and the yoke length $\left(L_{Y}\right)$.

$\begin{array}{ll}\quad \text { Reactions at the Yoke Leg Top } & \text { Reactions at the Yoke Leg Bottom } \\ \left.M=G_{(} W_{A} L_{A}\right) & M=G_{[} W_{A} L_{A}+\left(W_{A}+W_{F}+1 / 2 W_{Y} L_{Y}\right] \\ T=G\left(W_{A}\right)+T_{A} & T=G\left(W_{A}+W_{F}+W_{Y}\right)+T_{A} \\ V=G\left(W_{A}\right) & V=G\left(W_{A}+W_{F}+W_{Y}\right) \\ Q=G\left(W_{A} X_{A}\right)+Q_{A} & Q=G\left(W_{A} X_{A}\right)+Q_{A}\end{array}$

\section{Beam Mode Stress Analysis}

\section{Reactions to $T, V$, and $M$}

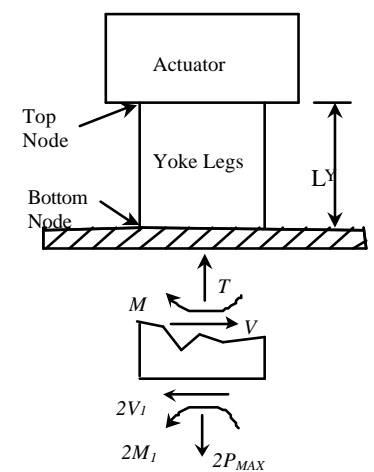

The beam mode assumes externa moment and Shear act orthogonal to the yoke window so that the legs behave like a cantilever beam. Stress is investigated at the legs bottom node, and the reaction forces at the bottom node are designated as $T$ (Thrust), $V$ (shear), $M$ (moment), and $Q$ (Torque).

$V_{1}=V / 2$

$V_{2}=Q /(2 Y)$

$V^{\prime}=V_{1}+V_{2}$

$M_{1}=M / 2$

$M_{2}=V_{2} L_{Y} / 2$

$M^{\prime}=M_{1}+M_{2}$

$P_{M A X}=T / 2$

$s=P_{M A X} / A+M^{\prime} X_{B} / I_{B}$

$t=V^{\prime} /(2 A / 3)$

$s_{E Q}=\left(s^{2}+3 t^{2}\right)^{1 / 2}$
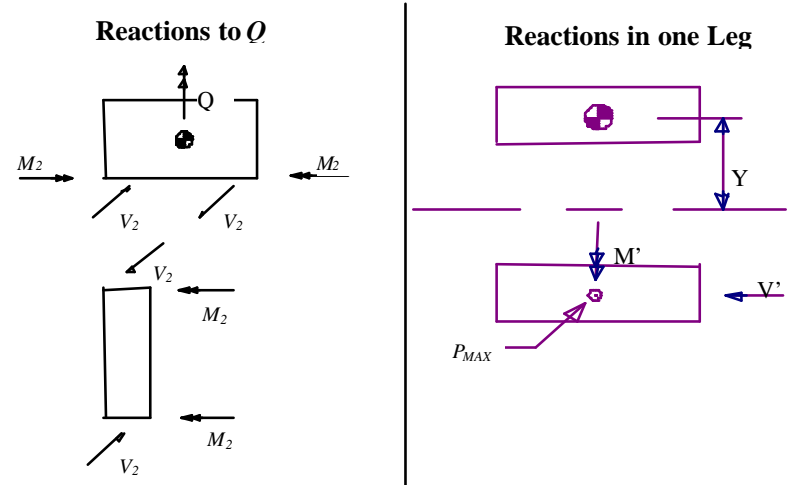

\section{Frame Mode Stress Analysis}

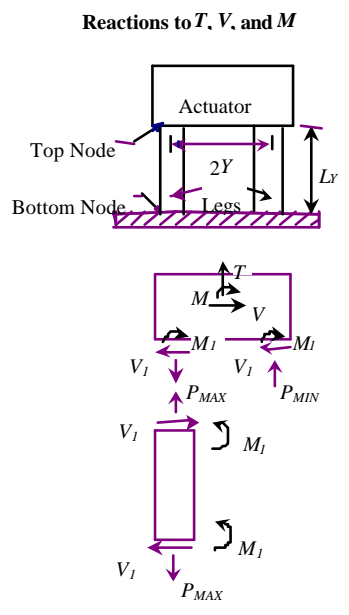

The frame mode assumes external moment and Shear act parallel with the yoke window so that the legs behave like a cantilever frame. Stress is approximately the same at the top and bottom nodes where it is a maximum. The appropriate reaction forces to employ are $T$ (hrust at the bottom (shear at the top node), $M$ (moment at the top node), and $Q$ (torque at the bottom node). Note that $Q$ causes leg reactions that are identical to that for the beam mode, and thus the previous torque free body diagram applies.

$V_{1}=V / 2$

$V_{2}=Q /(2 Y)$

$V^{\prime}=\left(V_{1}^{2}+V_{2}^{2}\right)^{1 / 2}$

$M_{1}=V_{1} L_{Y} / 2$

$M_{2}=V_{2} L_{Y} / 2$

$P_{M A X}=V L_{Y} /(2 Y)+M /(2 Y)+T / 2$

$S=P_{M A X} / A+M_{1} X_{F} / I_{F}+M_{2} X_{B} / I_{B}$

$t=V^{\prime} /(2 A / 3)$

$S_{E Q}=\left(S^{2}+3^{t 2}\right)^{1 / 2}$

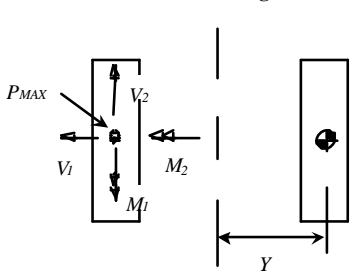

\section{A-3. Properties of Yoke Cross-Sections}

ARC TYPE, CROSS-SECTION CODE 101

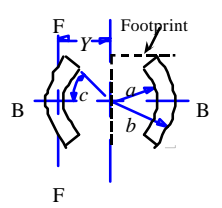

$$
\begin{aligned}
& A_{C S} \text { (Area of One Leg) } \\
& Y \text { (Centroid) } \\
& =(2 / 3) \sin (c)\left(b^{3}-a^{3}\right) / A c s \\
& I_{B} \text { (Beam Mode Inertia of One Leg) } \\
& =\left(b^{4}-a^{4}\right)(c-\sin (c) \cos (c)) / 4 \\
& I_{F} \text { (Frame Mode Inertia of One Leg) } \\
& =\left(b^{4}-a^{4}\right)(c+\sin (c) \cos (c)) / 4-A \quad c s Y^{2} \\
& X_{B} \text { (Beam Mode Extreme Fiber Distance) } \\
& =b \sin (c) \\
& =b[\cos (c)]-Y \\
& \text { FCS (Footprint) }
\end{aligned}
$$

BAR TYPE,CROSS-SECTIONCODE 5

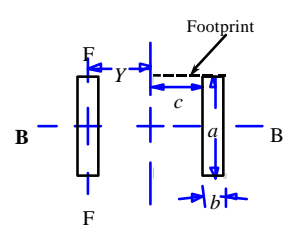

